\title{
Genome science and health disparities: a growing success story?
}

\author{
Charles Rotimi*, Daniel Shriner and Adebowale Adeyemo
}

Ten years after the completion of the Human Genome Project, researchers are using DNA to shed light on human history and health. A significant finding of the Human Genome Project and subsequent spin-off projects is that human populations are considerably more similar than different at the DNA level, yet it is now well recognized that genetic differences between ancestral and ethnic groups can have important evolutionary and medical relevance. Here, we reflect on how scientists are taking advantage of these observations to provide insight into complex social and medical issues, such as health disparities and variable drug response.

\section{Ethnic differences and health disparities}

Health disparities are differences in health status (such as incidence, prevalence, and mortality rates) between population groups. Health disparities depend on many factors, including age, gender, income, geography, ethnicity, and race. Overwhelmingly, disparities in health are the result of socio-political structures that drive some members of a society towards poorer health. Some have expressed concern that this gradient will be exacerbated if genetics draws attention and resources away from more important determinants of disparities [1]. Furthermore, because disparities can occur along ethnic and racial lines (at least in the US), genetic explanation may reinforce racial stereotypes, a known contributor to disparities. We recognize these pitfalls, but given the central role of DNA in disease etiology and variable drug response, the potential of genetics and genomics to shed light on health disparities must be considered.

High-throughput genomics has illuminated the relationship between ethnicity and disease disparities. Although most genetic variation is shared among all human populations, a disease susceptibility locus can differ in frequency across populations. To illustrate, African Americans typically trace ancestry to western Africa and

*Correspondence: rotimic@mail.nih.gov

Center for Research on Genomics and Global Health, National Human Genome Research Institute, NIH, Bethesda, MA 20892-5635, USA
Europe; this type of population of mixed ancestry is called admixed. In chromosomal segments containing disease susceptibility loci, there will be excess ancestry in an admixed population from the ancestral populations with higher frequencies of risk alleles. Admixture mapping became feasible in 2004 and has generated some notable successes. For example, the incidence of endstage renal disease (ESRD) is four times higher in African Americans than in European Americans. The hypothesis that susceptibility alleles for ESRD have higher frequencies in West African than European gene pools led to the identification of the Apolipoprotein L1 gene (APOL1) as a major effect gene [2]. Interestingly, the frequency of the APOL1 risk variant (rs73885319) varies worldwide, ranging from $40 \%$ among the Yoruba from Nigeria to $20 \%$ in African Americans and 0\% in Europeans and East Asians. This kidney disease risk variant is believed to have risen to high frequency in Africa because it confers resistance to trypanosomal infection and protects against the lethal form of African sleeping sickness.

Another example is differences in white blood cell (WBC) count, which have possible implications for disparity in cancer treatment and survival. Populations with African ancestry have lower WBC count than Europeans, and it has been suggested that lower WBC counts in African American women with early-stage breast cancer may lead to delays in treatment compared with European American women at a similar disease stage [3]. Approximately $20 \%$ of variation in peripheral WBC counts between African Americans and European Americans can be explained by the promoter-null variant rs 2814778 in the Duffy blood group gene DARC [4]. The derived allele $C$ is fixed between West Africans (frequency 100\%) and Europeans and East Asians (frequency 0\%); lack of genotypic variation within ancestral groups precludes detection via traditional genome-wide association studies.

Given such examples, methods that explicitly incorporate ancestrally specific effect sizes and differences in allele frequencies and linkage disequilibrium are being developed to empower studies of replication and better 
localization of disease risk variants across ancestral backgrounds. Furthermore, methodological advances now allow integration of admixture mapping and genotypic association, combining the power of the former with the resolution of the latter [5]. We anticipate that such techniques will help elucidate the genetic component of health disparities.

\section{Illuminating health disparities in the choice of and response to treatment}

Scientists are now beginning to document how pharmacogenomics variants can explain disparities in health outcomes. For example, warfarin is the most commonly used anticoagulant worldwide. However, it is characterized by a narrow therapeutic index and wide inter- and intra-individual variation in the dose required for the target therapeutic response. A small number of polymorphisms in CYP2C9 (alleles *2 and *3, rs1799853 and rs1057910, respectively) and VKORC1 (3673G>A, rs9923231) capture most of the pharmacogenomics effect on warfarin dose variance in white populations, but this is not so for populations of African ancestry, in whom VKORC1 rs9923231 and CYP2C9*2 and *3 are absent or rare [6]. The VKORC1 single nucleotide polymorphism rs9923231 is associated with reduced warfarin dose requirements in Asians, blacks, and whites. However, the percentage of inter-individual dose variation explained by this polymorphism is considerably lower in blacks (4.2\%) than in whites $(22.5 \%)$, which is largely due to the lower frequency of rs9923231 in the black study group (10.1\%) compared with whites (37.8\%) [7]. These allele frequency differences between populations translate to poor performance of warfarin dosing algorithms among populations of African ancestry when compared with Europeans.

Patients infected with hepatitis $C$ virus are usually treated with peginterferon and ribavirin to prevent sequelae such as progressive hepatic fibrosis, cirrhosis, and hepatocellular carcinoma. However, response to treatment is variable, and approximately half of such patients will achieve a sustained virological response after the standard course of treatment. African Americans are less likely to respond to treatment, independent of other host and viral factors. Genome-wide association studies led to the identification of single nucleotide polymorphisms in IL28B (such as rs12979860) as important predictors of treatment response and spontaneous clearance in patients infected with hepatitis $C$ virus. Allele frequencies differ between ethnic groups, largely explaining the observed differences in response rates between Caucasians, African Americans, and Asians. Indeed, the IL28B polymorphism may explain at least half of the difference in response rates observed between Caucasians and African Americans who received the same treatment [8].
A final example is acute lymphoblastic leukemia, a childhood cancer for which great strides have been made in successful treatment. However, poorer survival is observed among African Americans or those with Hispanic ethnicity compared with European Americans or Asians. A recent study in an unselected cohort of children with this form of leukemia found that Native American ancestry was associated with risk of relapse, after adjusting for known prognostic factors [9]. Remarkably, this ancestry-related difference in relapse risk was largely abolished by the addition of a single extra phase of chemotherapy.

\section{Conclusions}

The new knowledge allowing genomics to inform disease and treatment disparities across ethnic and continental ancestry populations stems directly from improvements in technology, tools, and methods from the Human Genome Project and related projects that enable us to interrogate the genome in a broad, flexible, and affordable way. We are just beginning to appreciate the potential role of pharmacogenomics in health disparities. Given the central role of treatment with pharmaceutical agents in modern medicine, it remains crucial to study multiple global populations as well as more drugs [10]. Such studies can find actionable observations that can be translated to treatment guidelines that maximize individual response while avoiding side effects and adverse drug reactions. In time, we will have sufficient knowledge to disentangle the genetic influences from the other broader behavioral, social, cultural, and health care access aspects of disparities in health outcomes.

\section{Abbreviations}

ESRD, end-stage renal disease; WBC, white blood cell.

Competing interests

The authors declare that they have no competing interests.

Published: 29 July 2013

\section{References}

1. Sankar P, Cho MK, Condit CM, Hunt LM, Koenig B, Marshall P, Lee SS, Spicer P: Genetic research and health disparities. JAMA 2004, 291:2985-2989.

2. Genovese G, Friedman DJ, Ross MD, Lecordier L, Uzureau P, Freedman BI, Bowden DW, Langefeld CD, Oleksyk TK, Uscinski Knob AL, Bernhardy AJ, Hicks PJ, Nelson GW, Vanhollebeke B, Winkler CA, Kopp JB, Pays E, Pollak MR: Association of trypanolytic ApoL1 variants with kidney disease in African Americans. Science 2010, 329:841-845.

3. Hershman D, Weinberg M, Rosner Z, Alexis K, Tiersten A, Grann VR, Troxel A Neugut Al: Ethnic neutropenia and treatment delay in African American women undergoing chemotherapy for early-stage breast cancer. J Natl Cancer Inst 2003, 95:1545-1548.

4. Nalls MA, Wilson JG, Patterson NJ, Tandon A, Zmuda JM, Huntsman S, Garcia M, Hu D, Li R, Beamer BA, Patel KV, Akylbekova EL, Files JC, Hardy CL, Buxbaum SG, Taylor HA, Reich D, Harris TB, Ziv E: Admixture mapping of white blood cell count: genetic locus responsible for lower white blood cell count in the Health ABC and Jackson Heart studies. Am J Hum Genet 2008, 82:81-87.

5. Shriner $D$, Adeyemo A, Rotimi CN: Joint ancestry and association testing in admixed individuals. PLoS Comput Biol 2011, 7:e1002325.

6. Suarez-Kurtz G, Botton MR: Pharmacogenetics of warfarin in populations of 
African descent. Br $J$ Clin Pharmacol 2012, 75:334-346

7. Limdi NA, Wadelius M, Cavallari L, Eriksson N, Crawford DC, Lee MT, Chen CH, Motsinger-Reif A, Sagreiya H, Liu N, Wu AH, Gage BF, Jorgensen A, Pirmohamed M, Shin JG, Suarez-Kurtz G, Kimmel SE, Johnson JA, Klein TE, Wagner MJ, International Warfarin Pharmacogenetics Consortium: Warfarin pharmacogenetics: a single VKORC1 polymorphism is predictive of dose across 3 racial groups. Blood 2010, 115:3827-3834.

8. Ge D, Fellay J, Thompson AJ, Simon JS, Shianna KV, Urban TJ, Heinzen EL, Qiu P, Bertelsen AH, Muir AJ, Sulkowski M, McHutchison JG, Goldstein DB: Genetic variation in IL28B predicts hepatitis C treatment-induced viral clearance. Nature 2009, 461:399-401.

9. Yang JJ, Cheng C, Devidas M, Cao X, Fan Y, Campana D, Yang W, Neale G, Cox NJ, Scheet P, Borowitz MJ, Winick NJ, Martin PL, Willman CL, Bowman WP,
Camitta BM, Carroll A, Reaman GH, Carroll WL, Loh M, Hunger SP, Pui CH, Evans WE, Relling MV: Ancestry and pharmacogenomics of relapse in acute lymphoblastic leukemia. Nat Genet 2011, 43:237-241.

10. Ramos E, Doumatey A, Elkahloun AG, Shriner D, Huang D, Chen G, Zhou J, McLeod H, Adeyemo A and Rotimi CN: Pharmacogenomics, ancestry and clinical decision making for global populations. Pharmacogenomics 2013. doi:10.1038/tpj.2013.24

\section{doi:10.1186/gm465}

Cite this article as: Rotimi $C$, et al: Genome science and health disparities: a growing success story? Genome Medicine 2013, 5:61. 